\title{
School Principals' Perceptions on Ebonics and Black English in Houston, TX
}

\author{
Garrard McClendon, Ph.D. \\ Associate Professor of Education \\ Cynthia Valenciano, Ph.D. \\ Professor Emeritus \\ Chicago State University \\ College of Education \\ United States of America
}

\begin{abstract}
This study investigated school principals' individual and aggregate perceptions of students who use African American Vernacular English in Houston, TX. Using the African American English Teacher Attitude Scale (AAETAS), the study seeks to describe the relationship between principals' demographic characteristics and their perceptions of African American Vernacular English. The study used raw scores from the AAETAS instrument created by Hoover, McNair-Knox, Lewis and Politzer (1997) and coded the principals' perceptions of AAVE. Principals' demographic information was gathered on the following categories: race, gender, age, language and dialect use of subjects, school enrollment, years teaching, years as an administrator, total employment years, and the aggregate mean of all principals' scores. These categories assist in highlighting perceptions and expectations among demographics. The results show an overall attitude of difference and mild acceptance. Four of the 44 principals (9.1\%) had a negative or deficit attitude toward AAVE. Thirty-two principals (72.7\%) were in the "Difference" category, meaning that listeners view AAVE as different and not necessarily negative. "Excellence" is a strong positive attitude towards AAVE. Eight out of 44 (18.2\%) principals were in this category. Because this is a qualitative study, the principals' responses have been explained through narrative. About 18\% of school principals in this study indicated that the dialect could be harmful to one's academic career, and they perceived $A A V E$ as a dialect they would prefer students not use.
\end{abstract}

\section{Introduction}

Teachers' and administrators' perceptions of students can be a factor in a schools' culture and climate: The more open the climate of the school, the less alienated students tend to be (Berg \& Cornell 2016; Hoy, 2008, p.1). Meaningful school improvement begins with cultural change, and cultural change begins with the school leader. Ebonics speaking students have a dialect dilemma - they must choose between a dialect that leads to economic and professional success, or the dialect they speak with family and friends and within their community (Godley \& Minnici, 2008). Many educators perceive Ebonics as inferior to Standard English, linguistically awkward and operating under a faulty grammar system (Ray,1995). The climate of negative attitude toward dialect can be significant. Four hundred years after Africans were forced to the Americas, language discrimination still exists. Studies have demonstrated that dialect can affect behavior, perception, and expectation.

\section{Purpose of the Study}

The purpose of this 2018 study was to investigate school principals in Houston, TX, and their perceptions and attitudes toward students who use language not considered standard, more specifically, African American Vernacular English. Craig (2002) stated that many African American students speak AAVE. There are numerous studies (Favors, 2017; Fogel, 2006; Isenbarger, 2006) that include teachers' attitudes and perceptions toward AAVE, which include the Ann Arbor, Michigan, Black English court case focusing on language barriers created by teachers' unconscious negative attitudes toward students' use of African American English, and the negative effect these attitudes have on student learning (Ball, 1997). Teachers' attitudes play crucial role in shaping the classroom environment, which has an impact on a students' self-esteem and behaviors (Daily, 2017; Dooly, 2005). Substantial literature (Blasé, 1999; Jonsberg, 2001; Hudson, 2001, Papageorge \& Kang, 2016; Aaron \& Powell, 1982) exists on teachers' expectations and perceptions, but little about administrators' perceptions. 
The purpose of this study was to collect Houston principals' perceptions and expectations, not to determine their effect on student performance. There may be conflicting views about empirical determinants, but African American students tend to be the outcasts in American schools - the group about which widespread notions of academic inferiority prevail (Ainsworth-Darnell \& Downey, 2005; Jencks \& Phillips, 1998; McWhorter, 2000; Steele, 1999). This phenomenon may extend to teachers' and principals' negative perceptions of the language that many Black students use. A review of the literature indicated a need for research on high school principals' perceptions of and expectations for students who use Black Vernacular English.

It is only appropriate that principals' perceptions of students' language skills be surveyed to gauge academic expectations against cultural biases. Self-fulfilling prophecies can influence teachers' decisions. According to Masland (1979), a teacher's bias against a student's Black English dialect may trigger lower teacher expectations and lower student performance.

According to Oates (2003), anti-Black bias among White teachers is more prevalent than the same bias from Black teachers. White teachers' perceptions are significantly more consequential to the performance of African American students (Ferguson, 1998). Claude Steele (2006) stated that a person's social identity defined as group membership in categories such as age, gender, religion, and ethnicity has significance when rooted in concrete situations (p. 1). Steele defined these situations as identity contingencies settings in which a person is treated according to a specific social identity.

\section{Research Design}

A 46-statement instrument was used to gather data on high school principals' perceptions and expectations of students who used AAVE. The African American English Teacher Attitude Scale (AAETAS) was used in this study. It is a four point, 46-item Likert Scale designed by Mary Rhodes Hoover, Faye McNair-Knox, Shirley Lewis, and Robert L. Politzer (1997). This study is an example of qualitative research. With qualitative research, one preserves chronological flow, sees precisely which events lead to which consequences, and derives fruitful explanations (Miles \& Huberman, 1994, p. 336).

\section{Procedures}

The methodological procedures used were the selection of the instrument, the selection of schools, the selection of subjects, the gathering of data, and the analysis of the data. The principals' demographic profiles were used to sort data in reference to each principal's ethnicity, principal's age, gender, and categories germane to the school climate. To triangulate data, the literature review sources were examined.

\section{Sample Population}

A volunteer sample of school principals in Houston was used for this study. Forty-four principals responded.

\section{Data Analysis}

The research questions that led the analysis of data are: 1) What perceptions did Houston school principals have concerning the use of Black Vernacular English by students in an academic setting? 2) What expectations did Houston school principals have concerning the use of Standard American English by students in an academic setting? From the data collected, trends surfaced and significant results concerning perceptions and expectations were obtained. This data allowed the researcher to study the principals, individually, in groups, and in aggregate. The researcher tallied and coded principals' attitudes based on the AAETAS. Because the test had 23 positive statements, 23 negative ones, and statements that pertained to multicultural acceptance, the researcher was able to immediately quantify and qualify data. The Likert-scale AAETAS and the Principal's Profile Form assisted in the process of finding relationships among data. Coded data were used to focus on qualitative relationships/outcomes and perceptions, not for specific numerical outcomes claiming empirical proof of attitudes. The following were contrasted for possible qualitative relationships: 1) principal's age, 2) administrator's ethnicity/race, and 3) gender of administrator, along with 4 additional categories.

\section{Principals' attitudes toward $\boldsymbol{A} \boldsymbol{A} \boldsymbol{V E}$}

The researcher was most concerned with the responses germane to attitudes towards AAVE. The overall mean score for principals was 133.14. See the following figures for principals' attitudes toward AAVE. 


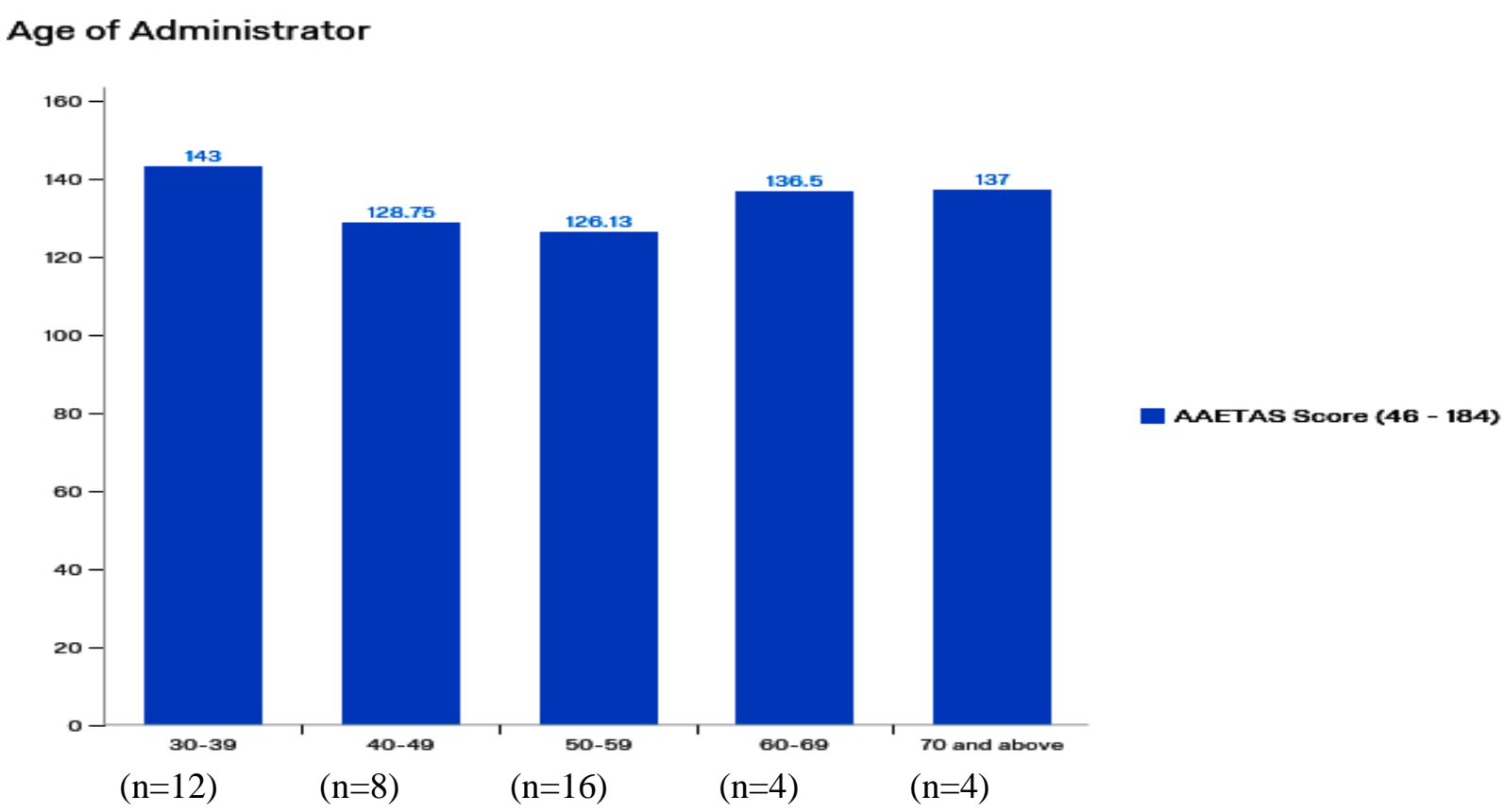

Figure 1. AAVE Acceptance by Principal's Age $(n=44)$

Of the 5 age groups surveyed in this study $(30-39,40-49,50-59,60-69,70+)$ younger administrators had higher acceptance than administrators in the middle of their careers. Administrators in their 30 have scored 143, and then a shift occurs with principals in their 40's and 50's. Acceptance of Black English decreases, and then heads upward when principals enter their 60's and 70'. Principals in their 40's have an average of 128.75, and in their 50's, we see the highest level at 126.13. As principals end their careers, the acceptance of AAVE increases again at the 60's (average score of 136.5), and principals over 70 years of age scored 137.

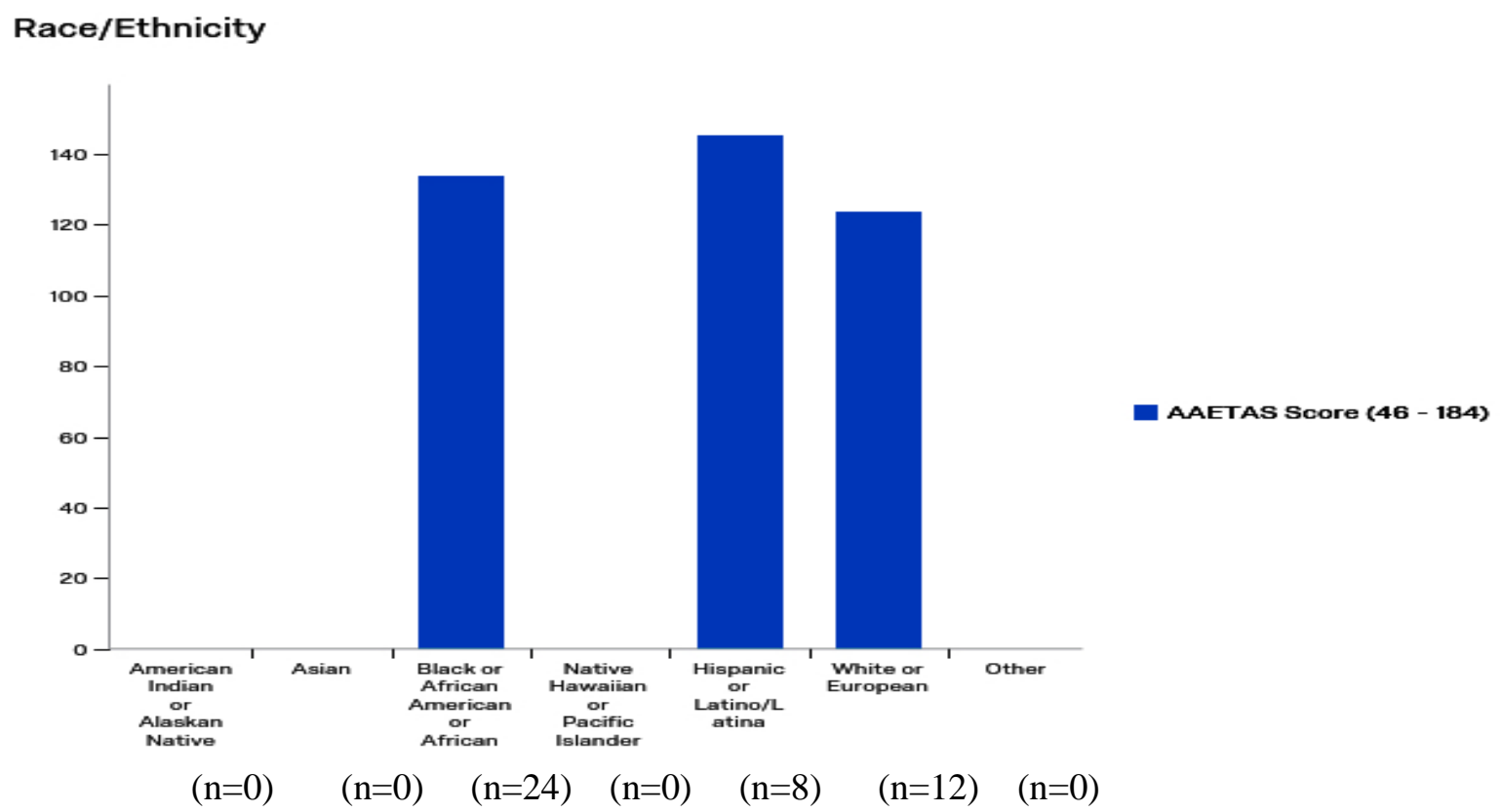

Figure 2. AAVE Acceptance by Principal's Race/Ethnicity $(n=44)$

African American principals had a mean score of 133.83 had a more positive perception of AAVE than White principals with a mean of 123.83. Latino/Latina principals' had a mean score much higher than both at 145 . 


\section{Gender of Administrator}

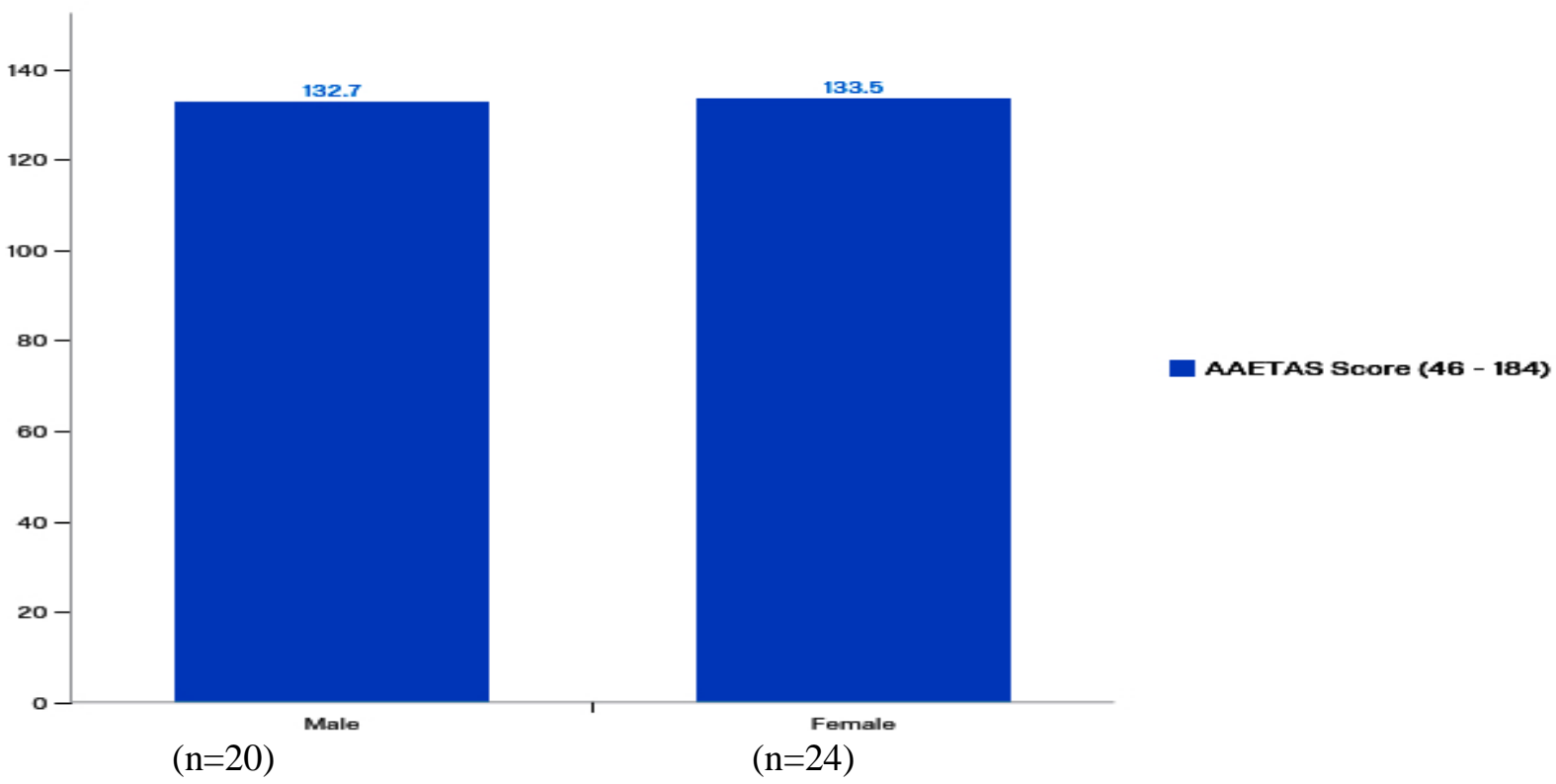

Figure 3. Attitude Toward AAVE by Gender $(n=44)$

Females were much more likely to show a more positive attitude to AAVE than males. The mean score for women was 133.5 and the scores for men totaled 132.7.

\section{Language Dialect Spoken at Home}

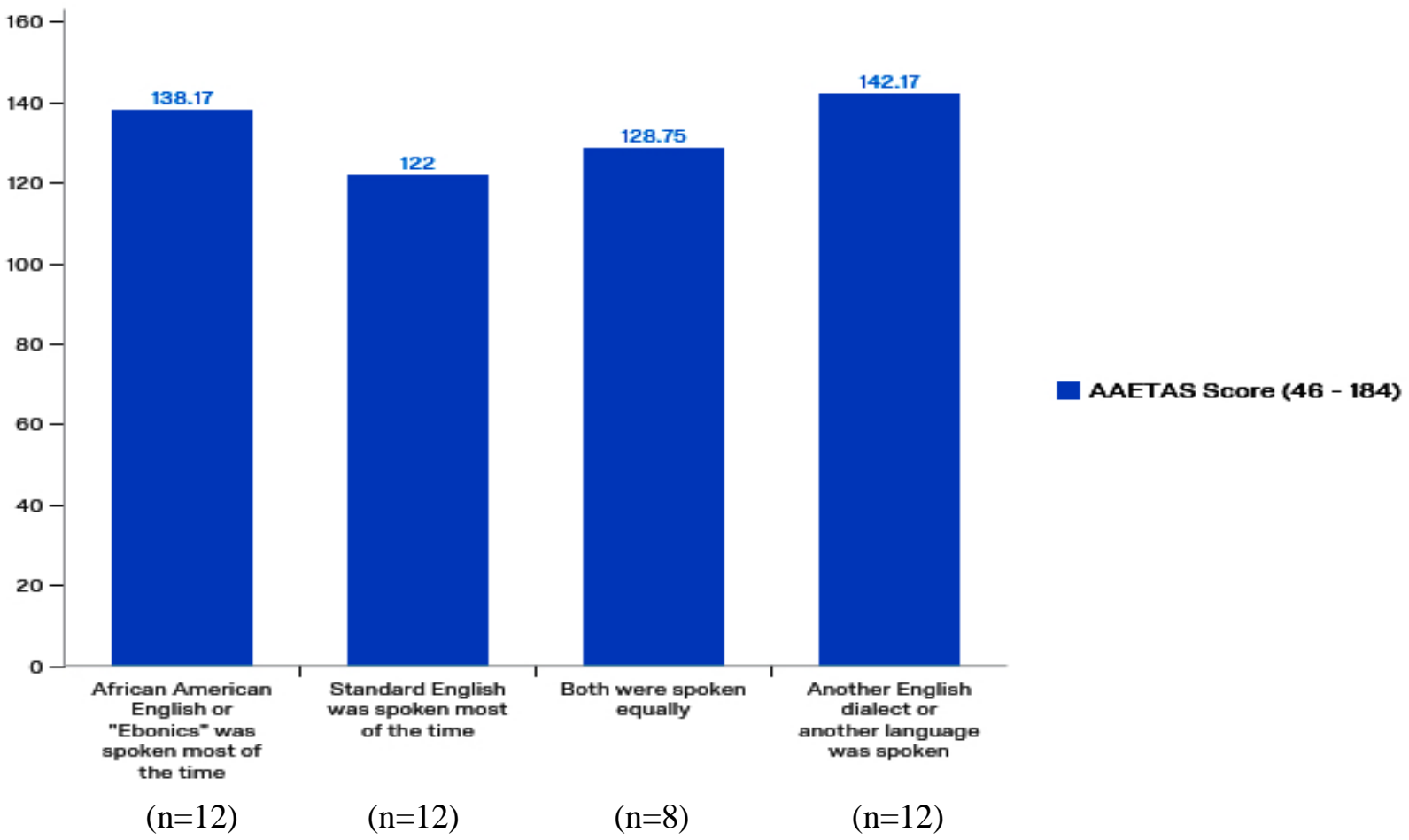

Figure 4. AAVE Acceptance by Principals' Home Language $(\mathrm{n}=44)$

With home language and AAVE acceptance, principals who spoke another language or another English dialect were the most favorable towards AAVE speakers.

Their mean score was 142.17. Principals who spoke AAVE/Ebonics most of the time in the home posted a mean score of 138.17. Principals speaking Standard English and AAVE scored 128.75. Principals speaking Standard English most of the time had the lowest mean score of 122. 


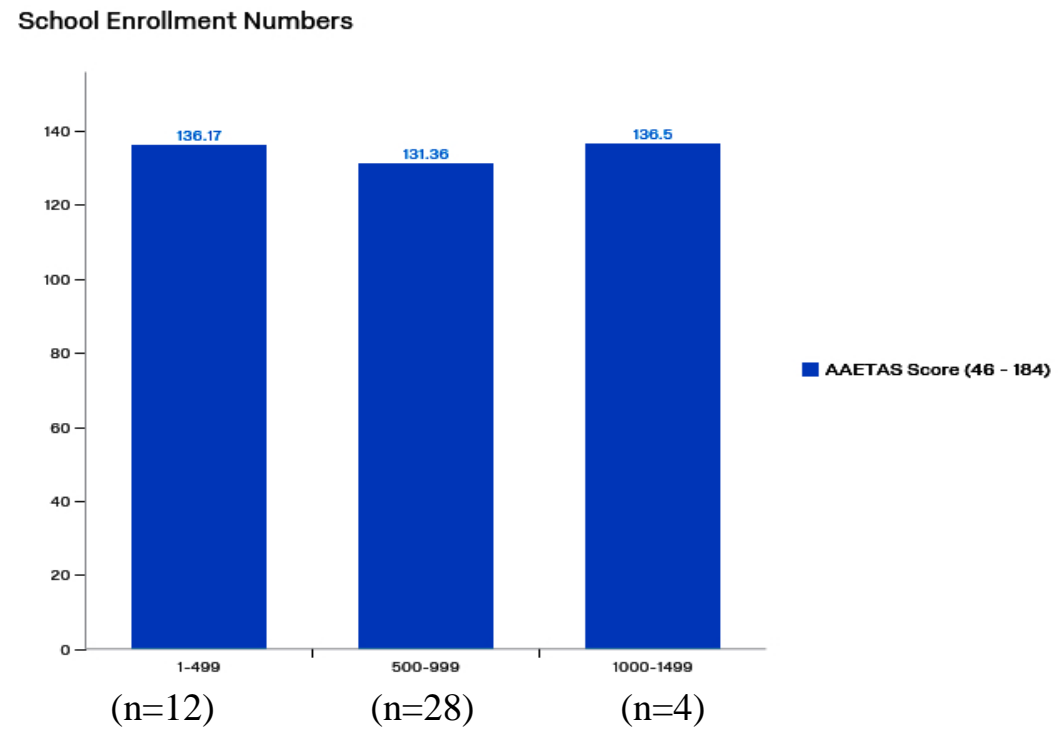

Figure 5. AAVE Acceptance by School Enrollment Size $(n=44)$

Principals in schools with student enrollment of 1-499 had an average attitude score of 136.17. Principals in schools with up to 500-999 students had an average attitude score of 131.36. Principals in schools with 1000-1499 students had an average attitude score of 136.5. Their acceptance was the highest.

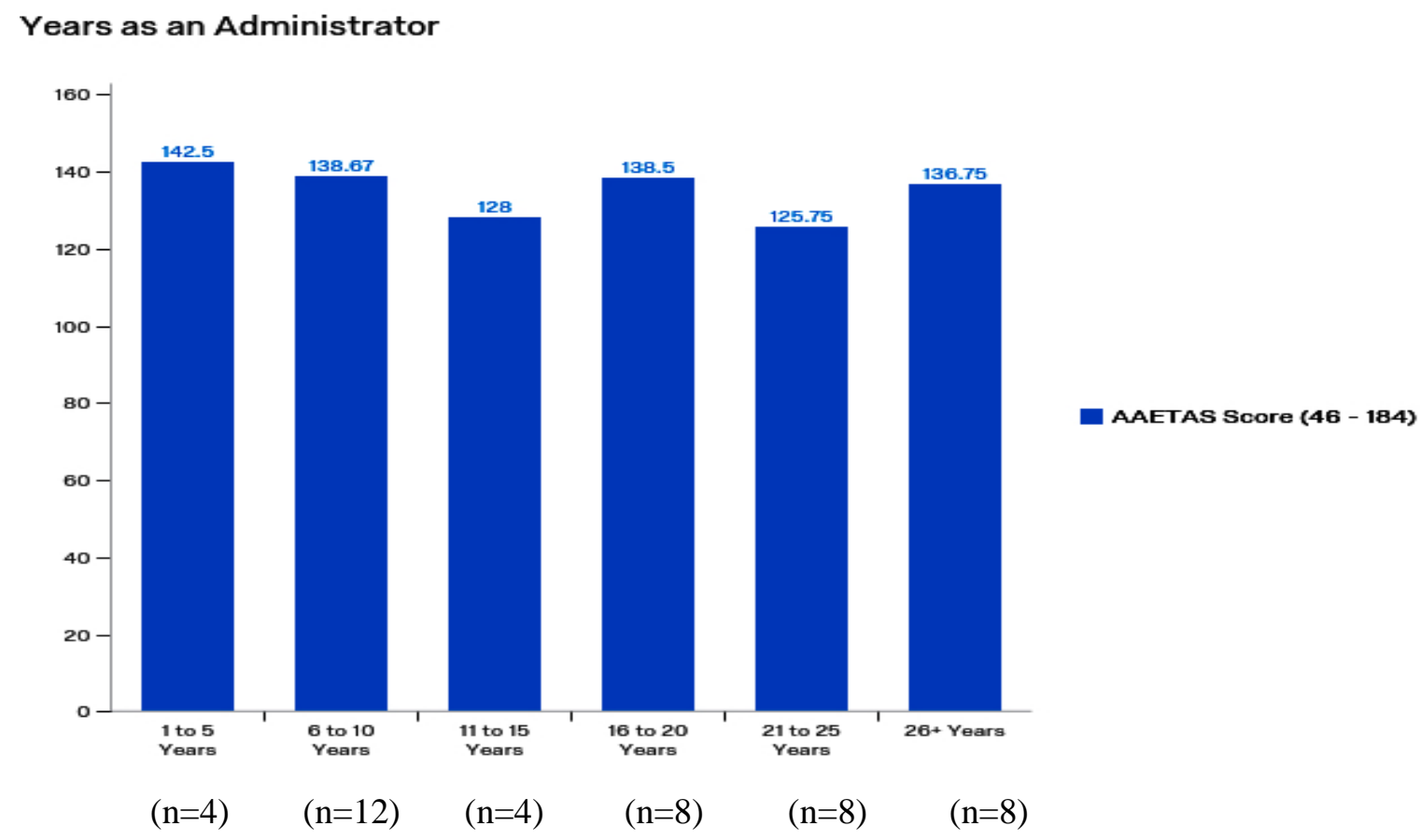

Figure 6. AAVE Acceptance - Years as an Administrator $(n=44)$

Principals with 1-5 years as an administrator had average raw scores of 142.5. Principals with 6-10 years scored 138.67, 11-15 years scored 128, 16-20 years scored 138.5, and 21-25 years scored 136.75. Principals with fewer years of administrative experience exhibited a more positive perception of speakers of AAVE. With experience, scores decrease until the 16thyear when an increase occurs. Scores dip and then increase again near the retirement years. 


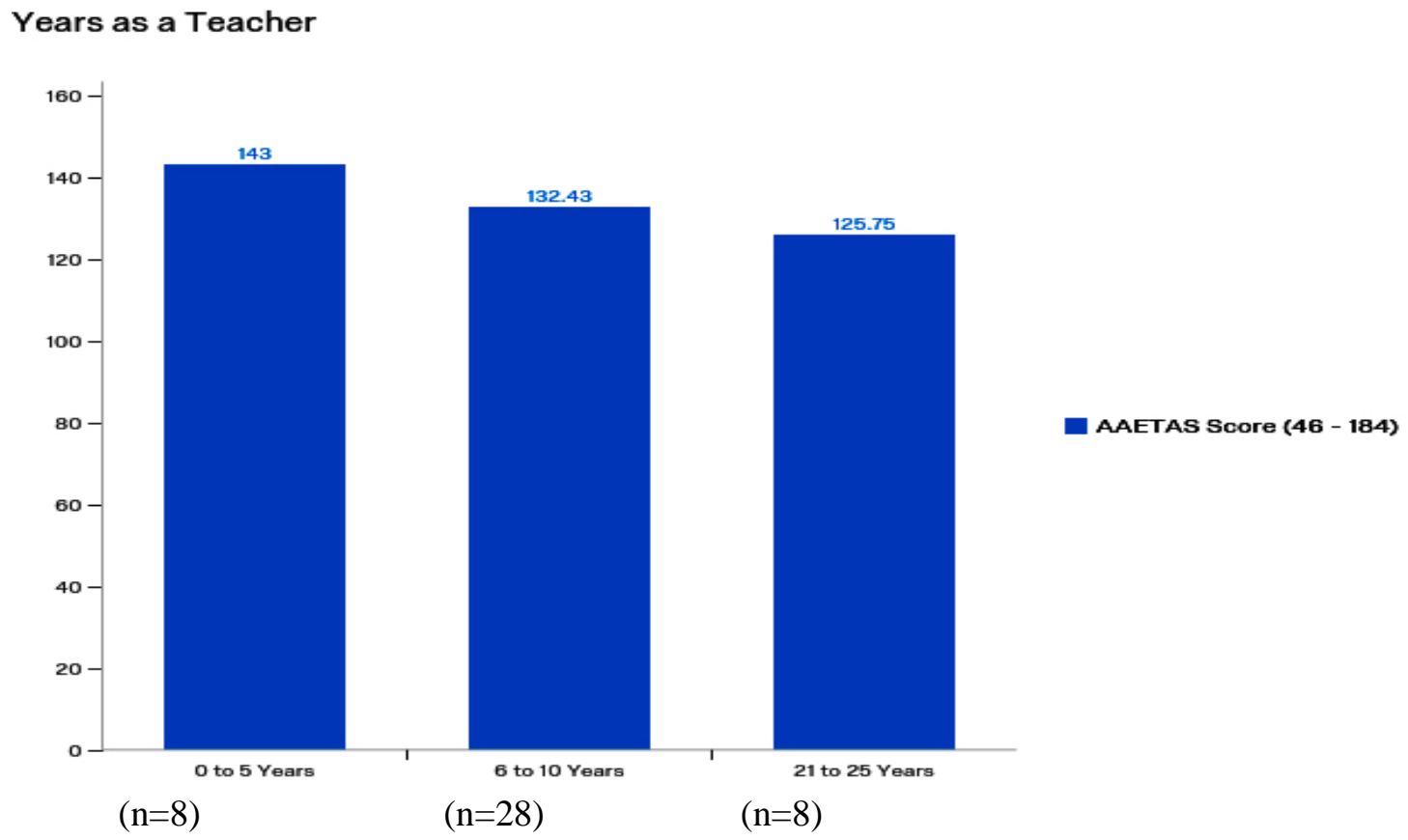

Figure 7. AAVE Acceptance - Years as a Teacher $(n=44)$

Principals with 0-5 years teaching experience had an average raw score of 143. Principals with 6-10 years scored 132.43, 11-15 years scored 132.43, and 21-25 years of teaching experience scored 125.75. With teaching experience, AAVE acceptance decreases over time.

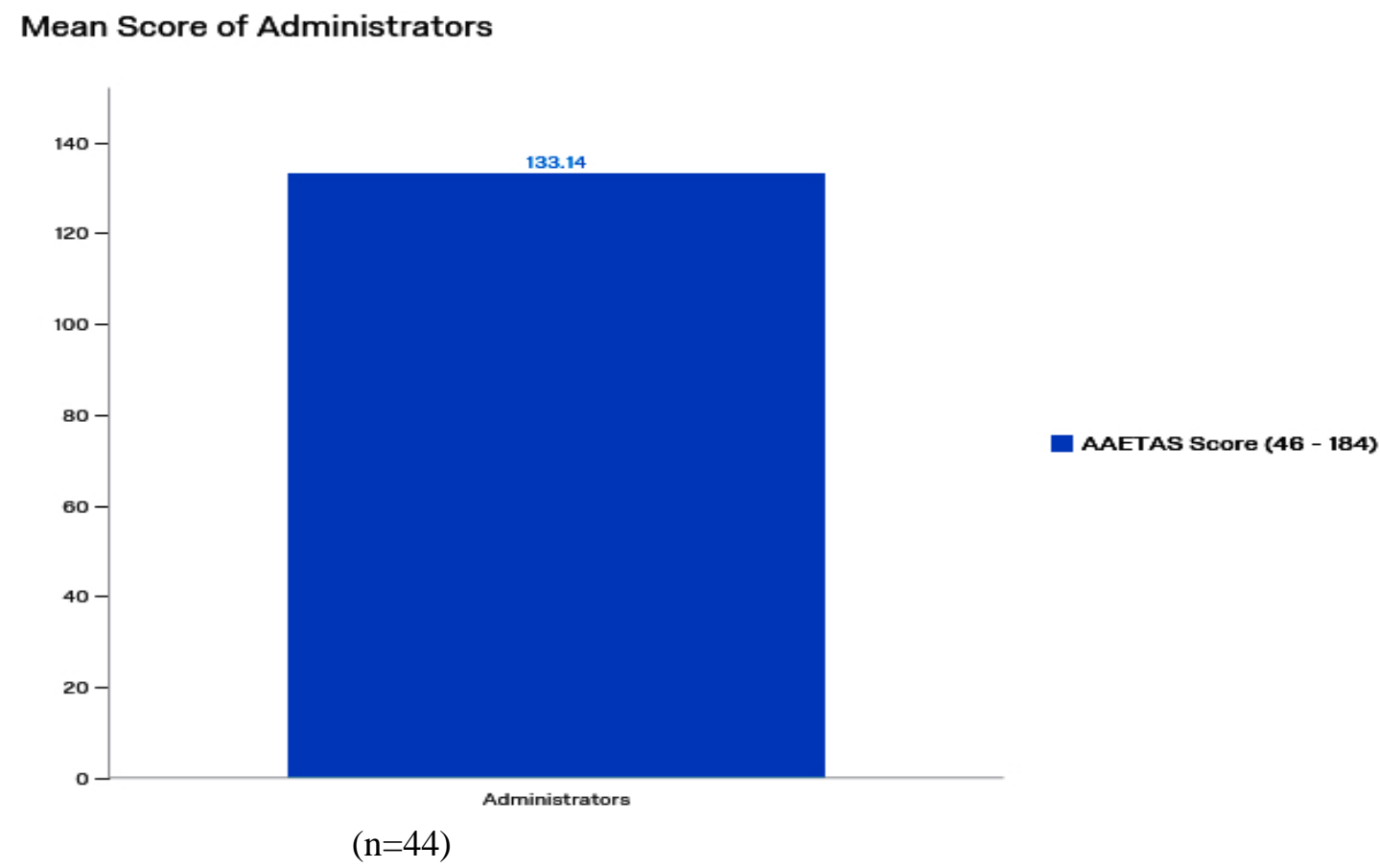

Figure 8. AAETAS Mean Scores for Houston Principals by Deficit, Difference, and Excellence (N=44)

The mean score for all administrators was 133.14.

\section{Final Reflections and Conclusions}

Overall, the findings in this study display evidence that most principals provide responses that show a neutral to mildly favorable perception of AAVE, and neutral to mildly positive expectations for students who use AAVE. Houston school principals view AAVE mildly positively, as reflected in the charts and instrument statement tallies noted above. However, there are selected categories and individual regions that show negative attitudes that may depict a lack of understanding, disagreement with, or ambivalence toward AAVE. 
The data in this study showed that the majority of principals were mildly positive toward AAVE. This was not consistent for all 44 participants. There were 4 who responded with an attitude considered deficit or negative according to the designers of the AAETAS. The principals did imply that code-switching was preferred to speaking AAVE all the time by their responses to the prompt "African Americans need to know both standard and Black English in order to survive in America." Twenty-eight principals agreed to this statement while only 12 disagreed. "Code-switching is the use of 2 or more linguistic varieties in the same conversation or interaction" (Myers-Scotton \& Ury, 1977). It is not random or meaningless. It has a role and function, often used as a key to communication (Greene and Walker, 2004).

\section{Discussion of Research Findings}

Nine percent of principals in this study indicated that the dialect could be harmful to one's academic career, andtheyperceivedAAVEasadialecttheywouldmildlypreferstudentsnotuse.Accordingtotheinstrument, a score at or less than 120 was considered "Deficit," or a strong negative attitude towards AAVE. Scores between 120 and 139 were considered "Difference," which meant that principals viewed AAVE as different and not negative. Raw scores of 140 and above were considered "Excellence," or a strong positive attitude towards AAVE. Because this is a qualitative study, the principals' affirmative and negative responses have been carefully described below.

Scores in the top 20\%, above 138, were deemed as more favorable. Although all languages should be accepted and considered equal, the reality is that Standard American English is what is expected by society (Isenbarger, 2006, p.127).

Redd and Webb (2005) discuss five methods used to teach AAVE speakers. The traditional approach focuses on immersing students in SAE, forbidding home/dialect language use, and explicitly teaching grammar. Second, the dialect approach is a modification of the traditional approach and borrows teaching strategies from English as a Second Language, while allowing code-switching (the ability to change or switch dialects depending on the situation, also known as bidialectism). Third, the dialect awareness approach is inspired by the idea that all forms of English are dialects and there should be no language prejudice; learning about all forms of English will add value to them. Fourth, the culturally appropriate approach centers on African American culture and uses Afrocentric resources, materials, content, etc. The fifth option is the bridge approach, which offers all students an opportunity to use their own language before transitioning to SAE, the U.S. standard for academic and professional writing (Redd and Webb, 2005, p.133). AAVE codeswitching pedagogy also can show similarities to second language learner strategies and contextual realities (Valenciano, 1999; Fernandez, Valenciano \& Garcia, 2013; Montes, 2018). The findings show that some principals have an aversion to African American Vernacular English according to the AAETAS. The researcher suggests that principals communicate with their teachers on how to instruct students on when to use Standard American English instead of AAVE. Administrators who have respect for students' language backgrounds will know that SAE may be the preferred dialect in professional settings, but they should respect the student's dialect as well. Each child brings their own personality and culture to school. Delpit says, "children have the right to their own language" (p.291, 1988). Administrators should embrace this right and share the respect for student culture, while ensuring that teachers promote SAE for the business world. Isenbarger states, "I believe in teaching the individual child, and tailoring instruction to his or her needs" (Isenbarger, p.130, 2006). The building leader has to expect and should deliver a value additive model. This is imperative for principals be- cause school climate and tone start with the building leader. Principals should prepare to lead teachers in code-switching training. Because some students do not speak standard American English in school, building principals can instruct their teachers to be sensitive to dialects, while maintaining a Standard English benchmark. The Stanford Center for Research and Development Center study compared the attitudes toward AAVE of in-service teachers in four cities (Trenton, NJ; New York, NY; Palo Alto, CA; and Miami, FL), using the AAETAS instrument (Hoover et al., 1977). The Hoover, Politzer, McNair-Knox, Lewis studies of 1977 and 1997, show similar attitudes. In the 1977 Stanford study of four cities, the mean raw score was 126.36, (Trenton 127.9, Palo Alto 137.9, New York 131.9, Miami 124), while scores in Ismail AbdulHakim's Florida A\&M study (2002) and McClendon's earlier Chicago study were 127 and 125.33, respectively. The mean for Houston was 133.14 which is higher than the State of Illinois study, the Chicago and Florida studies. These data show that the AAETAS is an instrument and that individuals in the education profession have similar attitudes across the country, in large cities and smaller towns.

Contribution to Research and Professional Practice 
This study offers a view of principals' attitudes concerning AAVE in the Houston metropolitan area. This study's examination of principals' attitudes can be particularly helpful, given that the AAETAS has been previously administered more to pre-service and in-service teachers than to building leaders. Professional practices can be enhanced through professional development workshops focusing on AAVE. Building principals who become aware of their expectations and perceptions of AAVE may be able to assist their faculty with strategies on how to develop a school climate that cultivates dialectic awareness and the bridge approach to teaching students Standard American English.

A principal, who shows respect for AAVE and its speakers, can gain the confidence to share methods on dialect code-switching in school, business, and casual environments. African American Vernacular English must be perceived as a valid, and respected dialect. However, teachers, principals, and parents alike must ensure that children are able to code-switch for the professional, business, academic, and mainstream English environments, so that opportunity exclusion doesn't become a factor.

\section{References}

Aaron, R. P. \& Powell, G. (1982). Feedback practices as a function of teacher and pupil race during reading group instruction. The Journal of Negro Education, 51 (1), 50-59.

Abdul-Hakim, I. (2002). Florida preservice teachers' attitudes toward African-American Vernacular English. (Doctoral dissertation, The Florida State University, 2002), Dissertation Abstracts International 64 (118).

Ainsworth-Darnell, K., Downey, D., \& Fischer, E.J. (2005). Black student achievement and the oppositional culture model. The Journal of Negro Education 74(3), 201-209.

Ball, A. \& Lardner, T. (Dec. 1997). Dispositions toward language: Teacher constructs of knowledge and the Ann Arbor Black English Case. College Composition and Communication Vol. 48, 4, 469-485.

Berg, J. K., \& Cornell, D. (2016). Authoritative school climate, aggression toward teachers, and teacher distress in middle school. School Psychology Quarterly, 31(1), 122-139.

Blase, J. (1999). Principals' instructional leadership and teacher development: Teachers' perspectives. Administration Quarterly, 35, 349-378.

Craig, H.K., \& Washington, J.A. (2002). Oral language expectations for African American preschoolers and kindergartners. American Journal of Speech-Language Pathology, 11, 59-70.

Daily Jr, D. L. (2017). Teachers' Attitudes Toward African American Vernacular English: A Quantitative Correlational Study (Doctoral dissertation, University of Phoenix).

Delpit, L. (1995). Other people's children: Cultural conflict in the classroom. New York: The New Press. Delpit, L. (1998). What should teachers do? Ebonics and culturally responsive instruction. In T. Perry \& L.

Delpit (Eds.), The real ebonics debate: Power language, and the education of African American children (pp. 1726). Boston, MA: Beacon Press.

Delpit, L., \& Dowdy, K. (2002). The skin that we speak: Thoughts on language and culture in the classroom. New York: The New Press.

Dooly, M. (2005). How aware are they? Research into teachers' attitudes about linguistic diversity. Language Awareness, 14 (2 and 3), 97-111.

Downey, D. B., \&Pribesh, S. (2004, October). When race matters: Teachers' evaluations of students' classroom behavior. Sociology of Education, 77, 267-282.

Favors, J. (2017). An Analysis of Black English (Ebonics). Black Lives Matter: Lifespan Perspectives, 108. Ferguson, R.F. (1998). Teachers' perceptions and expectations and the black-white test score gap. In C.

Jencks, \& M. Phillips (Eds.), The Black-White test score gap (pp. 273-317). Washington, DC: Brookings Institution.

Fernández, M., Valenciano, C., \& Garcia, M. I. (2013). Is Bilingual Education Moving Forward or Backward?. Towards Classroom Research: A Collaborative Vocabulary Research Study Vanessa Armand, Janice Ball, Claudia Kupiec, et al. 113, 93(1/2), 95.

Fogel, H.E. (2006). Teaching African American English forms to standard American English-speaking teachers. Journal of Teacher Education, 57(5), 464-480.

Foley, D. E. (1997). Deficit thinking models based on culture: The anthropological protest. In R. R. Valencia, The Evolution of Deficit Thinking (pp. 113-131). Washington, D.C.: The Falmer Press. 
Gay, G. (2005). Politics of multicultural teacher education. Journal of Teacher Education, 56(3), 221-228.

Godley, A. J., \&Minnici, A. (2008). Critical language pedagogy in an urban high school English class. Urban Education, 43(3), 319-346.

Greene, D. M., \& Walker, F. R. (2004). Recommendations to public speaking instructors for the negotiation of code-switching practices among black English-speaking African-American students. The Journal of Negro Education, 73(4), 435-442.

Hoover, M.R. (1978). Community attitudes towards Black English. Language in Society, 7, 65-87.

Hoover, M.R., McNair-Knox, F., Lewis, S.A.R., \&Politzer, R.L. (1997). African American English Attitude measures for teachers. In R. L. Jones (Ed.), Handbook of test and measurements for Black populations (383-393). Hampton, VA: Cobb and Henry Publishers.

Hoy, W.K. \&Miskel C.G. (2008). Educational administration: Theory, research and practice (8th ed.) New York: McGraw-Hill Education.

Hudson, B. H. (2001). African American female speech communities: Varieties of talk. Bergin \& Garvey.

Isenbarger, L. W., \& Ingram, A. (2006). An intersection of theory and practice: Accepting the language a child brings into the classroom. Language Arts, 84 (2), 125-135.

Jencks, C., \& Phillips, M. (Eds.). (1998). The Black-White test score gap: An introduction. Washington, DC: Brookings Institution.

Jonsberg, S. D. (2001). What's a (White) teacher to do about Black English? The English Journal, 90, 51-53.

Masland, R. L., Sarason, S. B., \& Gladwin, T. (1978). Mental subnormality. New York: Basic Books.

McWhorter, J. (1997). Wasting energy on an illusion: six months later. The Black Scholar, 27 (2), 2-5. Miles, M.B., \& Huberman, A.M. (1994). Qualitative data analysis: An expanded sourcebook (2nd ed.). Thousand Oaks, CA: Sage.

Montes, A. L. G., Valenciano, C. K., \& Fernandez, M. (2018). Training Bilingual Educators at a PBI. Multicultural Learning and Teaching, 13(1).

Myers-Scotton, C., \&Ury, W. (1977). "Bilingual Strategies: The Social Functions of Code-switching." Journal of the Sociology of Language. 13, 5-20.

Oates, G. (2003). Teacher-student racial congruence, teacher perceptions, and test performance. Social Science Quarterly, 84(3), 508-525.

Papageorge, N. W., Gershenson, S., \& Kang, K. (2016). Teacher expectations matter. IZA Discussion Paper No. 10165. Available at SSRN: https://ssrn.com/abstract=2834215

Ray, C. L. (1995). Changing Educators' Attitudes Towards Black English In The United States. Senior Investigative Paper, 1(1), 1st ser., 1-22.

Redd, T., \& Webb, K.S. (2005). A teacher's introduction to African American English: What a writing teacher should know. Urban, IL: National Council of Teachers of English.

Reeves, D. (2006). Leading to change: How do you change school culture. Association for Supervision and Curriculum Development, 64, 94.

Steele, C. (1992). Race and the schooling of African-American Americans. The Atlantic Monthly, April, 68- 78.

Steele, C. (1999). Thin Ice: Stereotype threat and Black college students. The Atlantic Monthly, August, 284(2), 44-47, 50-54.

Steele, C. (2004). Stereotype threat. Retrieved From https://www.mtholyoke.edu/offices/comm/c sj/092404/s teele.shtm

Valenciano, C. K. (1999). Teacher collaboration: A case study of teachers' contextual realities (Doctoral dissertation). University of Illinois at Chicago. 